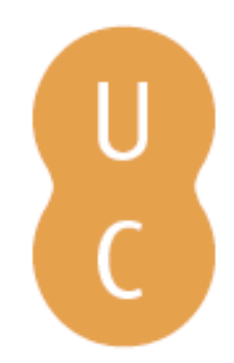

\title{
pommalina
}

\section{Do fim e dos homens: o ponto de vista dos militares sobre os últimos meses do} Estado Novo

Autor(es): $\quad$ Tornada, Joana de Matos

Publicado por: Imprensa da Universidade de Coimbra

URL

persistente: URI:http://hdl.handle.net/10316.2/31334

DOI: $\quad$ DOI:http://dx.doi.org/10.14195/978-989-26-0465-7_5

Accessed : $\quad$ 26-Apr-2023 14:59:03

A navegação consulta e descarregamento dos títulos inseridos nas Bibliotecas Digitais UC Digitalis, UC Pombalina e UC Impactum, pressupõem a aceitação plena e sem reservas dos Termos e Condições de Uso destas Bibliotecas Digitais, disponíveis em https://digitalis.uc.pt/pt-pt/termos.

Conforme exposto nos referidos Termos e Condições de Uso, o descarregamento de títulos de acesso restrito requer uma licença válida de autorização devendo o utilizador aceder ao(s) documento(s) a partir de um endereço de IP da instituição detentora da supramencionada licença.

Ao utilizador é apenas permitido o descarregamento para uso pessoal, pelo que o emprego do(s) título(s) descarregado(s) para outro fim, designadamente comercial, carece de autorização do respetivo autor ou editor da obra.

Na medida em que todas as obras da UC Digitalis se encontram protegidas pelo Código do Direito de Autor e Direitos Conexos e demais legislação aplicável, toda a cópia, parcial ou total, deste documento, nos casos em que é legalmente admitida, deverá conter ou fazer-se acompanhar por este aviso.

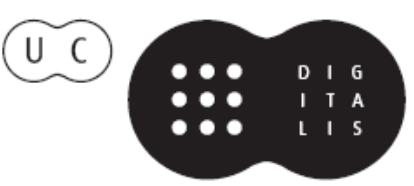




\section{R U I \\ C U N H A \\ M A R T I N S}

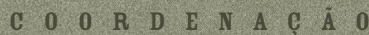

\section{PORTUGAL}
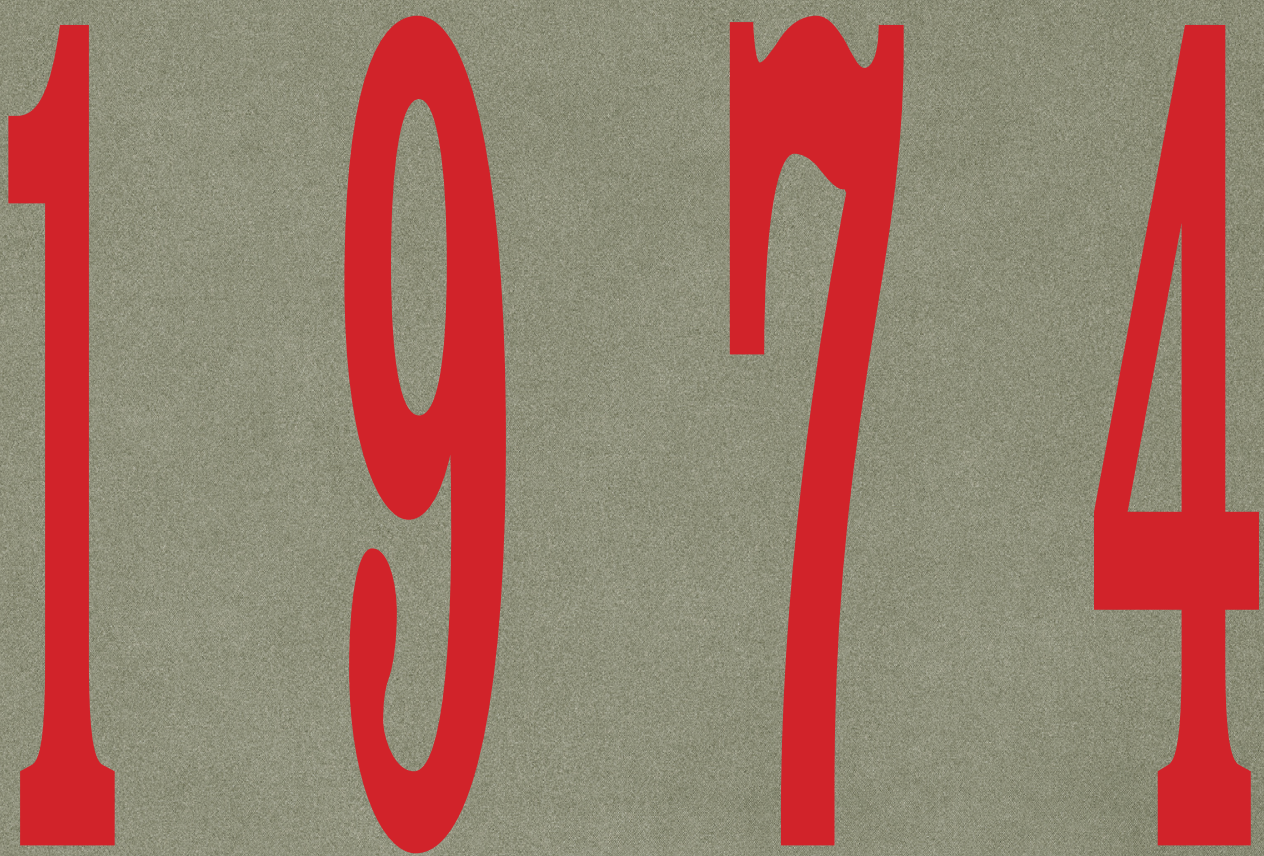

Transiçấo

PoLitica EM

Perspectiva

HISTÓRICA

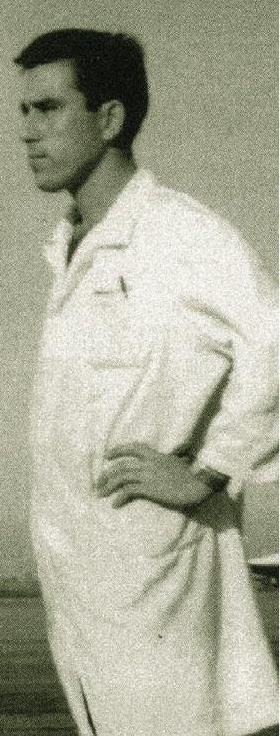




\section{DO FIM E DOS HOMENS: \\ O Ponto de Vista dos Militares \\ SOBRE OS Últimos Meses do Estado Novo}

JOANA DE MATOS TORNADA ${ }^{341}$

"Enquanto entidade global, a nação será menos brilhante, menos gloriosa e, talvez, menos forte, mas a maioria dos cidadãos usufruirá de um destino mais próspero". Alexis Tocqueville, Da Democracia na América, p.45.

O 25 de Abril de 74 apresenta-nos um problema historiográfico: como explicar a instauração da democracia portuguesa através de um golpe militar? Na génese desta questão reside, desde logo, um constrangimento. A instituição militar constituía uma das bases sólidas do Estado Novo. As Forças Armadas (FA) eram o símbolo da autoridade, da disciplina e da pátria. Todavia, foi no seu seio que emergiu o descontentamento e os bloqueios/ impasses catalisadores de uma acção armada. Este facto orienta a nossa reflexão em dois sentidos. Por um lado, perceber as dinâmicas sufocantes da agonia do regime, bem como as oportunidades abertas nas suas brechas. Por outro lado, é necessário conhecer bem os homens das FA, particularmente a massa humana que protagonizou a Guerra Colonial.

\footnotetext{
${ }^{341}$ Mestre em História Contemporânea pela Universidade de Coimbra.
} 
O problema do Ultramar, a sua complexidade e intensidade, gerou dinâmicas conflituantes. Influenciados pelos ventos de mudança dos Estados Unidos e Europa, os jovens portugueses começaram a manifestar um certo antimilitarismo humanista. Ou seja, as FA, como instituição e até como carreira, tinham vindo a perder a sua atração. Na Academia Militar, todos os anos, reduzia-se o número de candidatos. Concomitantemente, a sua doutrina perde o seu peso elitista. Apesar de todo este desmoronamento da instituição militar, prevalecia o mito da Nação, a função glorificadora das FA, defensoras da Pátria. É, talvez, aqui, que reside a sua queda.

A vivência da Guerra Colonial portuguesa desabou esta estrutura, já frágil. As dúvidas e incertezas dos militares contrapuseram-se à inflexibilidade da estratégia político-militar do Estado Novo. Apesar de se verificar, sobretudo, uma forte politização dos oficiais milicianos, as conversas sobre o país, o seu estado e os seus homens, faziam então parte do quotidiano de quase todos os militares. Esta cumplicidade reforçou, por um lado, a consciência colectiva dos homens das FA. Embora, por outro, tenha destruído a crença na apoliticidade dos mesmos. As dúvidas foram-se cimentando e quebrando a firmeza das decisões políticas. A quem servia este conflito (chacina, massacre)? Para que fim morriam ou ficavam mutilados camaradas? Que Pátria se defendia em África? Compreender o trajecto dos militares de Abril é compreender, desde logo, que este quadro de interrogações se torna, a certa altura, incontornável.

\section{A ascensão dos homens de Abril}

As raízes da contestação dos militares evidenciam-se, em 1973, por ocasião do I Congresso dos Combatentes. Contra este acontecimento surgiu um abaixo-assinado dinamizado por oficiais próximos do General Spínola, que fácil e rapidamente obtiveram cerca de 400 assinaturas - a primeira manifestação da consciência dos oficiais das FA portuguesas e do impasse criado pela Guerra Colonial. O Governo não reage, oferecendo um amplo espaço aos mesmos oficiais. Porém, a génese do Movimento das Forças Armadas (MFA) emergiu do "colete-de-forças" que constituiu a publicação 
dos decretos sobre a promoção das carreiras dos oficiais oriundos de milicianos. Este documento é polémico, porque, desde logo, o Ministério do Exército não escondeu a sua finalidade: "minimizar o problema existente no Exército da carência de oficiais"342. Na Nota-Circular n. ${ }^{\circ} 490$, divulgada em todos os quartéis, é referido o clima emocional intenso e o descontentamento dos oficiais contestatários. Mais, esta circular retrata com fidelidade o ambiente sentido no Exército, referindo o desgaste físico sentido de uma forma agravante pelos oficiais do Quadro Permanente (QP); bem como a urgência do aumento do número de oficiais no contexto da Guerra Colonial.

Desde o início da vigência do Estado Novo que os oficiais milicianos desempenharam um papel importante nas FA portuguesas. "Tendo procedido, por motivos económicos e políticos, à compressão do Corpo de Oficiais do quadro permanente, e porque o quantitativo de elementos do mesmo quadro era reconhecidamente insuficiente para assegurar o funcionamento da organização militar, dispôs Salazar ao recurso maciço a oficiais milicianos" 343 . Ora se o número de oficiais desde os anos 30 era reduzido, quando, em 1961, o Presidente do Conselho declarou ao país que "Vamos para Angola rapidamente e em força" foi despoletado um processo complexo que alterou a instituição pilar do regime ${ }^{344}$.

O Ministro da Defesa Nacional e do Exército, o General Sá Viana Rebelo, no seu discurso na Escola Prática de Infantaria (EPI), em Setembro de 1973, aproveitou para advogar a sua solução política face ao desgaste da luta de 12 anos no Ultramar. "Nestes 12 anos de luta no Ultramar pode-se afirmar

\footnotetext{
${ }^{342}$ Ministério do Exército, Repartição do Gabinete do Ministro, Nota-Circular n. ${ }^{\circ}$ 490/S Proc. 14.66, Lisboa, 14 de Setembro de 1973.

343 Maria Carrilho, Forças armadas e mudança política em Portugal no séc. Xx: para uma explicação sociológica do papel dos militares, Imprensa Nacional da Casa da Moeda, Lisboa, 1985, p.400.

${ }^{344}$ Inicialmente, o oficial miliciano que pretendia ingressar na Academia Militar tinha que fazer exames preparatórios e frequentar um curso semelhante àqueles que entravam directamente na instituição. Com a Guerra Colonial, o Governo criou um curso especial, mais breve do que na Academia. Além disso, teriam de frequentar um estágio numa das Escolas Práticas, bem como deveriam ter tido uma comissão no Ultramar, de pelo menos dois anos. Nenhuma destas condições alterava o sistema de antiguidade, salvaguardando os oficiais oriundos de cadetes (veja-se Idem, Ibidem, pp. 400-408).
} 
que quem tem sofrido o peso principal das operações militares tem sido o quadro permanente das Forças de Terra, Mar e Ar".345

O ministro louvou o esforço dos oficiais e sargentos milicianos, embora declarasse que a guerra pesava mais nos ombros dos oficiais do QP, graças às várias comissões militares que se realizavam em três cenários diferentes, ano após ano. Logo estudava uma solução mais equilibrada para estes oficiais no sentido do seu "refrescamento" através dos milicianos. "Por outro lado os Oficiais que cursam normalmente a Academia Militar, terão sempre a seu favor a menor idade, a melhor preparação, e as melhores condições para bem se situarem nos concursos, provas e colocações de serviço em que é fértil a carreira militar. Não serão prejudicados nem, como é evidente tal se deseja". 346

A importância política dos milicianos, ou seja, a sua utilização como peça do jogo político, surgiu com maior acuidade após a Grande Guerra. "Entre os factos causadores de perturbação a nível das normas profissionais já adquiridas no seio da instituição militar, reveste-se de especial gravidade a questão dos milicianos formados no período da guerra"347. Esta afirmação de Maria Carrilho refere-se ao período da I Guerra Mundial. O oficial miliciano era geralmente um jovem estudante com o diploma do secundário atraído pelas regalias e direitos atribuídos a um oficial do QP, mas também pelas suas habilitações. Na verdade, estes oficiais preenchiam a necessidade de homens que a guerra estendida por África impunha.

Em 1921, foi publicada legislação que permitia que estes oficiais integrassem um quadro especial, embora, em circunstâncias particulares pudessem integrar o QP. Estes diplomas enquadravam-se num período em que "terminada a guerra, os movimentos insurreccionais pró - monárquicos obrigam os governos republicanos a manter a necessidade de um dilatado número de quadros no Exército, não se procedendo então, em Portugal, à redução do efectivo número de oficiais verificada nos outros países euro-

\footnotetext{
345 "O Ministro da Defesa e do Exército em Mafra", Jornal do Exército, Setembro de 1973.

${ }^{346}$ Idem, Ibidem.

${ }^{347}$ Maria Carrilho, Forças armadas e mudança política em Portugal no séc. xx: para uma explicação sociológica do papel dos militares, p. 241.
} 
peus. Por outro lado, convinha aos governos reforçar o sector dos oficiais favoráveis ao regime (...)"348 reconhecendo o esforço daqueles que interromperam as suas vidas para o defender. Todavia, neste período, esta decisão provocou alguma perturbação e descontentamento no Corpo de Oficiais, que indirectamente criticavam os oficiais de milicianos causadores do decréscimo do seu prestígio. Maria Carrilho conclui: "este processo - de ideologização - evitando questionar frontalmente os aspectos materiais, desenvolvendo-se no espaço das superstruturas, onde investe, como veremos, o tema da acção global, nacional das autoridades governativas e, portanto, a esfera governativa". 349

Também, decorridos 13 anos de política ultramarina ofensiva eram exigidos enormes esforços às FA. Confiante que "em meados de 1973 a situação militar podia considerar-se satisfatória”350, para Marcello Caetano a evolução decisiva residia na falta de rigor na defesa de Portugal e "era unânime a opinião de que só abrindo largamente a carreira das armas aos milicianos que tivessem dado boas provas em campanhas se poderia solucionar a crise". ${ }^{351}$ O governo do Estado Novo viu no aproveitamento da experiência de guerra destes militares, que tinham cumprido o serviço militar obrigatório (jovens mais instruídos e filhos da classe média), a forma mais rápida de garantir a continuação da sua estratégia militar, sem comprometer a base política que a sustentava.

Nos anos 60, vários cursos especiais foram criados para capitães milicianos. O coronel Virgílio Varela afirma que foi confrontado com "decretos-lei que aliciavam oficiais milicianos a passarem para o Quadro Permanente. O que não foi cumprido, nem a própria lei do Serviço Militar!"352 Desde 1968, tentavam sensibilizar forças políticas para os seus interesses. Contactaram

${ }^{348}$ Idem, Ibidem, p. 242.

${ }^{349}$ Idem, Ibidem, p. 244.

350 Marcello Caetano, Depoimento, Distribuidora Record, Rio de Janeiro e São Paulo, 1974, p. 179.

${ }^{351}$ Idem, Ibidem, p. 184.

352 Virgílio Varela refere-se à forma como se sente lesado, por não reconhecerem, para efeitos de antiguidade, o período que cumpriu como oficial miliciano (ou seja, enquanto cumpria o Serviço Militar Obrigatório). 
deputados e jornalistas e distribuíram panfletos, mas poucos perceberam que a sua reivindicação poderia desestabilizar as instituições militar e política.

Estes militares perceberam que o seu problema só seria resolvido com um grande apoio político. "Estava-se já na fase de distanciamento do regime, do qual sabiam que já nada podiam esperar". 353 . A Comissão Conjunta dos Oficiais do Q.P. oriundos do Q.C. e dos Oficiais do Q.E.O. enviou um conjunto de documentos aos deputados da Ala Liberal, bem como aos directores de alguns jornais na tentativa de ver cumprida a legislação aprovada anteriormente pela Assembleia Nacional ${ }^{354}$. Além disso, procuraram diversos apoios à sua causa, inclusive nos combatentes civis, que poderiam participar no Congresso dos Combatentes realizado de 1 a 3 de Junho de $1973^{355}$.

Os oficiais oriundos de milicianos eram menos e estavam dispersos por um país pluricontinental. Virgílio Varela ${ }^{356}$ assumiu desde cedo certo pro-

353 Josep Sánchez Cervelló, A Revolução Portuguesa e a sua influência na transição espanhola (1961 - 1976), Assírio e Alvim, Lisboa, 1993, p. 163.

${ }^{354}$ Era enviado um pequeno Memorandum onde explicitavam a sua situação profissional, nomeadamente as diversas vias de acesso aos quadros de Oficiais do Exército, bem como um breve cronologia dos vários documentos oficiais publicados referidos ao tema. Em anexo era incluído o Doc. N. ${ }^{\circ} 1$ - Despacho n. ${ }^{\circ} 6$ do Ministro do Exército publicado a 7 de Novembro de 1961, Doc. N. ${ }^{\circ}-$ Excerto da Lei do Serviço Militar (n. ${ }^{\circ} 135$ ) publicada a 11 de Julho de 1968, Doc. N. ${ }^{\circ} 3$ - Circular convidando os Oficiais do Quadro Especial de Oficiais a frequentarem um curso na Academia Militar datada de 12 de Julho de 1973, Doc. N. ${ }^{\circ} 4$ - Decreto-lei no 353/73 de 13 de Julho de 1973 que veio a dar força de lei à anterior circular, Doc. N. ${ }^{\circ} 5$ - Decreto - Lei n. ${ }^{\circ 409 / 73}$ que complementa e confirma o diploma anterior, N. 6 - Circular do Ministro do Exército datada de 20 de Agosto de 1973 alertando que a contestação dos diplomas anteriores fica ao abrigo do Regulamento de Disciplina Militar, Doc. N. ${ }^{\circ} 7$ - Nota circular n. ${ }^{\circ}$ 409/S do Ministério do Exército que esclarece os propósitos dos diplomas em vigor, datada de 14 de Setembro de 1973 (sobre o qual afirmam "Trata-se de um documento muito importante pelo que é fundamental a sua leitura integral e atenta”), Doc. N. 8 Decreto - Lei 685/73 publicado a 21 de Dezembro de 1973 que restabelece a situação dos oficiais do Q.P. oriundos do Q.C. nos mesmos termos que se encontrava em 1961.

355 "Ainda tentámos apoiá-los, mas, quando começou a ter um cariz demasiado fascista, nós desistimos de qualquer acção em conjunto". Entrevista com o coronel Virgílio Varela (1992) in Manuel A. Bernardo, Marcello e Spinola: a Ruptura. As Forças Armadas e a Imprensa na Queda do Estado Novo 1973 - 1974, Editorial Estampa, Lisboa, 1996, p. 323.

${ }^{356}$ Este militar foi promovido a alferes miliciano, a 1 de Novembro de 1961. A 1 de Dezembro de 1964, foi promovido a tenente miliciano. Quando saiu da Academia Militar era aspirante graduado em tenente. Fez o tirocínio e passou a alferes graduado em tenente, a 1 de Janeiro de 1969. Só adquiriu a graduação de tenente, a 1 de Dezembro de 1970. Desde 1968, ano em que concluiu a 
tagonismo. "Só havia uma razão, capaz de arrancar simultaneamente todo o grupo. Era reivindicar, como direito dos oficiais milicianos, a manutenção do posto e respectiva antiguidade já adquirida. Não os perdendo, quando tirassem o curso da Academia Militar e integrassem no Quadro Permanente". 357 Em Julho de 1973, viram as suas reivindicações cumpridas. Porém, estas não se fundamentaram na justiça que procuraram, mas sim na agonia das FA e na impotência do poder político.

A publicação dos decretos em Julho de 1973 gerou a constituição de dois grupos distintos. O grupo dos oficiais oriundos de milicianos, que finalmente via confirmada a salvaguarda dos seus intentos, não viu com bons olhos a onda de contestação do grupo dos oficiais oriundos de cadetes. Porém este cresceu com alicerces mais profundos.

Embora, historicamente, a génese do Movimento dos Capitães se situe na contestação dos referidos diplomas, Otelo Saraiva de Carvalho afirma que, desde o seu início, se associaram motivados por questões, também, políticas. Nestes decretos-lei, os oficiais do quadro reconheciam o aproveitamento desesperado da oportunidade pelo Governo. Com o intuito de continuar a guerra seguindo a mesma estratégia político-militar, recorriam aos oriundos de milicianos para colmatar a falta de capitães com formação técnica especializada, procurando fixá-los a uma dedicação vitalícia. Daí que conclua que "o Movimento dos Capitães nunca foi contra os oficiais oriundos de milicianos. Nós fomos inimigos do regime, que permitia isto. Se não há meios para continuar a guerra colonial parem, acabou! Não há mais guerra colonial porque não há meios materiais e humanos para continuar a guerra!"358

\footnotetext{
Academia Militar, lhe foi negado o reconhecimento do tempo de serviço enquanto ali esteve, embora se manifestasse junto das instâncias militares. Esta situação obrigou-o a aguardar que os oficiais do seu curso atingissem o posto de capitão para ascender a esta posição. No entanto, já o possuía desde o seu serviço militar obrigatório. Foi o sentimento desta injustiça que o levou a procurar outros oficiais na mesma situação e a escrever alguns panfletos.

${ }^{357}$ Entrevista com o coronel Virgílio Varela (1992) in Idem, Ibidem, p. 318. Com a legislação em vigor antes dos decretos de Julho de 1973, os oficiais milicianos conservavam a sua patente a nível salarial e frequentavam um curso abreviado na Academia Militar porque a sua experiência de guerra conferiu-lhes alguns créditos. No entanto, cada oficial deste grupo beneficiou de circunstâncias particulares.
}

${ }^{358}$ Entrevista com o Coronel Saraiva de Carvalho, em Lisboa, a 4 de Julho de 2007. 
$\mathrm{Na}$ verdade, para Vasco Lourenço ${ }^{359}$ o Movimento dos Capitães resultou da reacção ao Congresso dos Combatentes de alguns oficiais que contestavam politicamente o regime. A publicação do decreto apenas originou a organização dos oficias que aproveitavam o impacto da reacção de Julho. Noutro sentido, analisa José Medeiros Ferreira o Movimento. Fala de diferentes fases. A primeira situa-se entre Junho e Dezembro de 1973 e é marcadamente corporativa. O processo de politização dos Capitães não foi automático e provocou o afastamento de alguns oficiais, os que defendiam uma via legalista em oposição àqueles que apelavam à urgência de encontrar uma solução política para a guerra colonial conduzindo a um inevitável derrube do regime. A segunda fase situa-se entre Dezembro de 1973 e 5 de Março de 1974. No mini plenário de Cascais os elementos do Movimento dos Oficiais das Forças Armadas (MOFA) definiram o seu ideal político: democracia e descolonização. Eram estes os objectivos da sua luta.

A publicação dos decretos, expressão de uma necessidade política e militar conservadora e nacionalista, incentivou a associação dos oficiais (ou melhor, a sua divisão em dois grupos unidos), bem como o seu espírito reivindicativo; é nestes documentos que residem as vésperas da desarticulação e desagregação quer das FA, quer das autoridades políticas.

Viana de Lemos condena a publicação dos decretos. Não porque lhes reconhece um poder contestatário (no sentido de permitir uma certa desautorização da legitimidade da hierarquia), mas sim reivindicativo. Reclama da opção das autoridades militares, pois considera-a reflexo da "péssima política de recrutamento para o Exército"360. Mais, afirma que recebeu requerimentos de alguns oficiais do Serviço Cartográfico, contestando a "arbitrariedade" desta publicação. Os documentos seguiam para a Repartição de Oficiais do Exército, mas permaneceram sob a indiferença do ministro Sá Viana e Rebelo e subsecretário de Estado do Exército. Nota, ainda, que através do relato do major Albuquerque de Castro teve conhecimento da

\footnotetext{
${ }^{359}$ In 30 anos do 25 de Abril, coord. de Manuel Barão cunha, Casa das Letras, Cruz Quebrada, 2005,pp. 31-55

360 Viana de Lemos, Lemos, Duas Crises: 1961 e 1974, Nova Gente, Lisboa, 1977,p. 64.
} 
reunião de Alcáçovas, comunicando-o, de seguida, ao general Viotti de Carvalho, vice-chefe de Estado-Maior do Exército.

O seu testemunho evidencia como o Governo e as autoridades militares conheciam de perto as movimentações e razões do Movimento dos Capitães. As chefias sabiam-no, mas ignoravam-no. Paradoxo? Os oficiais requeriam, seguiam a via legalista, mas não eram ouvidos. Esta situação confusa abria cisões dentro do Exército, despoletando actos de rebelião. Para Viana de Lemos, o Movimento começou com um protesto corporativo, mal conduzido pelas chefias que não lhe reconheceram a concretização da perda de prestígio e hierarquia das $\mathrm{FA}^{361}$.

Em Novembro de 1973, a demissão do ministro Sá Viana e Rebelo e subsecretário de Estado do Exército demonstrou a força e capacidade do Movimento. Mais, em Dezembro, aumentaram os vencimentos dos oficiais. O processo de politização dos jovens capitães foi progressivo, embora bastante rápido. As pequenas vitórias fomentaram a sua força e consciência. Só depois surgiu a opção pelo derrube do regime. Em causa estava o prestígio das FA abalado por um guerra longa e sobre a qual se esgotavam as soluções políticas.

No mês anterior os decretos foram revogados. O grupo dos oficiais oriundos de milicianos reuniu-se em Porto de Mós. O Coronel Virgílio Varela recorda que foi necessário "convencer os 40 oficiais que lá apareceram, para em vez de pedirem aquilo que tinha sido prometido a cada um, trabalharem em conjunto e encontrar uma forma legítima para resolver o problema que existia". Pretendiam o restabelecimento da lei de 1928, que premiava os oficiais milicianos que tinham participado na I Guerra Mundial”362.

O factor corporativo é importante na mobilização inicial e deu força à concretização de algumas acções colectivas, criando um movimento organizado $^{363}$. A união que sobressaiu da reacção à publicação dos decretos

361 Viana de Lemos declara, ainda, que conversava com regularidade com o General Costa Gomes sobre o problema dos capitães. Entre os dois prevalecia um acordo de concordância com o seu protesto.

362 Entrevista com o Coronel Virgílio Varela, em Lisboa, a 7 de Maio de 2007.

363 Circula entre os oficiais do QP oriundos de cadetes uma exposição - tipo destinada a enviar ao Ministério do Exército. Foi elaborada pelo capitão Morais da Silva e procura salvaguardar o prestígio militar, posto em causa pelo D.L. no 353/73 de Julho de 73 em revisão. O decreto 
resulta da lenta e progressiva consciencialização de alguns $^{364}$ nas suas potencialidades e na possibilidade de o transformar num movimento político ${ }^{365}$. A 2 de Novembro de 1973 iniciam-se os contactos entre os dois movimentos, no sentido de uma possível colaboração ${ }^{366}$. Todavia, ambos os grupos agitam as suas esferas de influência para reforçarem o seu poder reivindicativo.

Os oficiais oriundos de cadetes fundaram, a 1 de Dezembro de 1973, uma nova fase do Movimento dos Capitães. Os jovens oficiais afastaram-se das iniciais razões corporativas e entravam numa fase marcadamente política. Desde logo constituíram uma Comissão Coordenadora constituída por 19 membros, três por cada arma ou serviço militar, distribuíram funções e, mais tarde, na reunião da Costa da Caparica, a 5 de Dezembro, elegeram subcomissões executivas. Ao mesmo tempo que se definiram como um grupo conspirativo, também se aperceberam que a unidade dos oficiais do QP e dos oficiais milicianos era fundamental: “(...) qualquer cisão podia ter graves consequências nas operações militares em curso em África”.367

Por sua vez, com a revogação dos decretos, os oficiais oriundos de milicianos procuraram outros canais de influência no sentido de satisfazerem as suas aspirações corporativas. O seu movimento iniciou, em Dezembro de 1973, uma forte ligação com o General Spínola. O Capitão António

409/73 introduz alterações que apenas beneficiam os majores. A situação dos capitães permanece inalterável. Após algumas reuniões é constituída a Comissão do Movimento dos Capitães na Guiné formada pelos capitães Almeida Coimbra, Matos Gomes, Duran Clemente e António Caetano. Oficiais do QP ( 45 capitães e 6 patentes mais baixas) em serviço na Guiné dirigem ao Presidente da República, ao Presidente do Conselho e aos Ministros da Defesa Nacional do Exército e da Educação Nacional, e ainda ao Secretário de Estado do Exército, uma exposição. Entre os nomes que assinam o documento figuram Manuel Monge, Salgueiro Maia e Otelo Saraiva de Carvalho.

${ }^{364}$ A 12 de Novembro de 1973 realizou-se uma reunião da Comissão Coordenadora prevalecendo a sua demissão devido a cisões no seu seio.

365 A 24 de Novembro de 1973 decorreu uma reunião do Movimento dos Capitães, no Estoril, na Casa da Cerca em S. Pedro do Estoril. Participaram 45 oficiais representantes das principais unidades do país. O Movimento entrou numa fase marcadamente política.

366 A 2 de Novembro de 1973 foi enviado um novo comunicado do Movimento em que se referem contactos com capitães oriundos de milicianos, no sentido de uma colaboração futura. Enquanto, a 11 de Novembro de 1973, ocorreu um encontro entre os capitães Diniz de Almeida (ex-cadete) e Alberto Ferreira (ex-miliciano) para resolver o conflito existente entre oficiais de carreira e oficiais milicianos.

367 Sanches Osório, O Equivoco do 25 de Abril, Editorial Intervenção, Lisboa, 1975, p. 20. 
Ramos, seu ajudante de campo, tornou-se num bom aliado. Nesta altura, contactou o General comunicando-lhe as razões destes oficiais. O Capitão mencionou a existência de duas Comissões Coordenadoras. Uma constituída por oficiais oriundos de cadetes e outra por oficiais oriundos de milicianos ${ }^{368}$, divididas pela questão das antiguidades. O oficial general toma conhecimento do grupo, mas não se fideliza aos seus intentos ${ }^{369}$.

O General conhecia bem o esforço e empenho dos oficiais milicianos, bem como a dificuldade que a falta de oficiais profissionais causava à guerra colonial. A questão da antiguidade criou um difícil divisionismo (os oficiais oriundos de milicianos sentiam-se afectados por um claro elitismo) e um clima de generalizada contestação (por sua vez, os oficiais oriundos de cadetes consideraram que estava em causa o prestígio das FA). Spínola jogou a sua habilidade e inteligência no modo como seguiu os dois movimentos. "Entretanto, fui acompanhando, através do Capitão António Ramos, o desenrolar do processo, nomeadamente a intenção de alguns oficiais fazerem convergir os esforços das duas coordenadoras, o que, segundo o mesmo oficial, se revelava extremamente difícil devido ao radicalismo de alguns dos seus camaradas". 370

Na reunião da Costa da Caparica, o capitão António Ramos comunicou a disponibilidade do general para os defender e ouvir porque pretendia como vice-CEMGFA resolver o problema dos decretos. Assim, o capitão "(...) entendeu por bem iniciarmos a recolha de assinaturas do pessoal do nosso grupo espalhado por todas as unidades, que seriam levadas ao general Spínola. No frontispício das várias folhas de assinaturas afirmava-se

368 "O meu primeiro contacto com o Movimento ou, mais precisamente, com um das suas facções, ocorreu em meados de Dezembro de 1973, quando o Capitão António Ramos - meu futuro ajudante-de-campo - me visitou em minha casa e me revelou as intenções reivindicativas dos oficiais do Quadro Permanente oriundos do Quadro de Complemento, por causa da promulgação dos últimos decretos relacionados com a sua inclusão na escala de antiguidades".In António de Spínola, País sem Rumo - Contributo para a História de uma Revolução, Editorial SCIRE, s. 1., 1978, p.89.

369 "Depois de ter ouvido as suas ideias sobre o assunto, não refreei os seus entusiasmos mas também não os incentivei, tendo-o informado de que em breve seria nomeado Vice-Chefe do Estado - Maior General das Forças Armadas, momento a partir do qual não me furtaria a receber a todos os oficiais que me procurassem".In Idem, Ibidem, p.89.

370 Idem, Ibidem, p.90. 
que a partir daquele momento estaríamos ao dispor do velho General para a solução Nacional que ele entendesse por mais conveniente para o País".371 Reuniram centenas de assinaturas ${ }^{372}$ e consolidaram a ligação deste pequeno, mas importante grupo, ao general (declaravam que "desde já se comprometem e se solidarizam com qualquer posição que Vossa Excelência possa vir a tomar, com vista a debelar a INJUSTIÇA e a elevar o prestígio das Forças Armadas"373).

Spínola recebeu, no início de Janeiro, uma delegação da Comissão dos Oficiais oriundos de milicianos. O general recorda que "limitaram-se a pedir-me para advogar a sua causa junto do Governo, ao mesmo tempo que me entregaram um documento, subscrito por cerca de duas centenas de oficiais, mandatando-os para tratar dos seus assuntos profissionais. Sugeri-lhes, então, que se reunissem com a Comissão representativa dos capitães oriundos de cadetes, a fim de estudarem em conjunto uma proposta que satisfizesse as duas partes, a qual me deveria ser entregue e constituiria a minha base de trabalho".374

Igualmente, pediu o General "que aguardássemos calmamente até à sua tomada de posse como vice - CEMGFA, a partir da qual estaria em condições de encontrar a melhor solução para os nossos problemas de antiguidade" 375 . Solicitou, ainda, que se apresentassem em força no Estado Maior General das FA, no dia da sua tomada de posse. Um grupo de destacados oficiais da Comissão dos Oficiais oriundos de milicianos participou na cerimónia, a 17 de Janeiro de 1974.

${ }^{371}$ Armando Marques Ramos entrevistado pela revista Tradições, "A verdadeira história do Golpe das Caldas", Tradições, Junho de 2004, n. ${ }^{\circ} 6$, Lisboa, p. 6.

372 "Era um facto que tínhamos uma relação especial com Spínola porque o seu ajudante de campo era um oficial oriundo de miliciano e podíamos passar as mensagens que quiséssemos. Fizemos um abaixo-assinado e contactei pessoas que não conhecia. Eu com o Silva carvalho fomos a Pombal à meia-noite para um oficial oriundo de milicianos assinar". Afirmações do Coronel Virgílio Varela em entrevista, em Lisboa, em 25 de Junho de 2007.

373 Documento reproduzido na obra de António de Spínola, País sem Rumo - Contributo para a História de uma Revolução, p.387.

${ }^{374}$ Idem, Ibidem, p.91.

375 Armando Marques Ramos entrevistado pela revista Tradições, Art. Cit., p.6. 
No dia 21 de Janeiro o major Otelo Saraiva de Carvalho e o capitão Vasco Lourenço foram recebidos no seu gabinete na Cova da Moura. Em Dezembro de 1973, o Movimento dos Capitães assumiu-se um grupo de pressão constituído. Daí que Kaúlza de Arriaga os tenha procurado para apoiarem o seu golpe. Mas os capitães colaboraram na denúncia deste, aproximando-se dos generais Costa Gomes e Spínola. Para Melo Antunes "[em Dezembro de 1973] o movimento tinha um carácter claramente corporativo e com preocupações profissionais. (...) Mas foi sobretudo a partir desta denúncia feita pelo Fabião que percebi que podia facilmente politizar-se o movimento, porque, tal como o Kaúlza estava a querer aproveitar-se desta agitação e o descontentamento existente entre os oficiais para os conduzir a uma acção política que pusesse em causa o regime, mas para o endurecer (dada a despolitização generalizada dos oficiais), essa acção podia também ter o sentido inverso (...)"376.

Os oficiais oriundos de cadetes, junto do general, na presença do seu ajudante-de-campo informaram-no dos acontecimentos de Moçambique. Spínola reiterou a defesa do prestígio das Forças Armadas e que tudo estava a ser feito para o esclarecimento dos acontecimentos e tomada de medidas imediatas. Desde logo, esclareceu que apenas os apoiaria caso se mantivessem nos limites da disciplina e estrutura militar, considerando não haver "necessidade de utilizar a via panfletária que considerava pouco própria de militares de carreira". 377

O General Spínola esclarece que as altas hierarquias militares tinham conhecimento da existência do Movimento dos Capitães, mas que desprezavam as suas potencialidades optando pela manutenção dos seus princípios. "Já, então, me tinha apercebido claramente de que, perante a incapacidade do Governo para solucionar a gravíssima crise político-militar em que nos debatíamos, o ainda incipiente "Movimento dos Capitães» era irreversível, pois baseava-se em razões indiscutivelmente válidas, havendo, portanto, que orientá-lo no sentido de o transformar em força útil junto dos chefes milita-

\footnotetext{
376 Melo Antunes, entrevistado por Maria Manuela Cruzeiro, Melo Antunes - O Sonhador Pragmático, Editorial Notícias, Lisboa, Lisboa, 2a edição, 2004, pp. 48-49.

377 António Spínola, País sem Rumo - Contributo para a História de uma Revolução, p.92.
} 
res responsáveis, forçando estes a uma tomada de posição".378 Com o problema da falta de confiança dos escalões inferiores nos seus comandantes, nomeados para o cargo não por mérito, mas por confiança política (demonstração de subserviência, incapazes de criar soluções) “(...) tudo se encaminhava no sentido de, mais dia menos dia, aqueles comandantes serem marginalizados pelos escalões inferiores de um movimento revolucionário de imprevisíveis consequências". 379

As escolhas dos oficiais e do general denunciam o fim do Estado Novo. A sua queda não resultou exclusivamente do desgaste dos seus homens. O seu desmoronamento foi progressivo e consequente da indiferença da sua autoridade. As chefias militares deixaram escapar a sua legitimidade, que foi sendo canalizada para os dois generais, mas também se foi dissipando pelo corpo de oficiais. A habilidade destes foi fundamental.

Movimentando-se entre questões corporativas, ao mesmo tempo que discutindo política; recorrendo à via legalista do requerimento e das manifestações; contrariando a proibição da livre associação, o Movimento foi fruto de uma certa inconsciência, na determinação em não dar pretextos fáceis para uma reacção violenta e generalizada quer do poder político, hierarquia militar e PIDE. Por outro lado estavam convencidos que o poder político dificilmente confrontaria elementos das FA, sinal inequívoco da desagregação do regime. Por sua vez, a polícia política concentrava-se na oposição comunista ou de movimentos de libertação. Os jovens capitães ainda não tinham entrado em ruptura com o regime, embora a situação tenha acelerado a degradação do poder político e das hierarquias militares. A politização do Movimento, feita com extraordinária rapidez, poderá evidenciar que as suas motivações escondiam razões de natureza política.

É nesta luta, nas suas angústias e sonhos, que reconhecemos a massa humana da história vivida da guerra colonial, mas também os homens que se precipitaram nas Caldas da Rainha. A saída extemporânea da coluna sublevada extravasa em muito as leituras posteriores que a encerram nas dinâmicas spinolistas. A emancipação política dos oficiais do Exército ul-

\footnotetext{
${ }^{378}$ Idem, Ibidem, p.93.

379 Idem, Ibidem, p.94.
} 
trapassou os dois generais e as suas esferas de influência, dado que se enraíza, sobretudo, na sua experiência colonial (mesmo se a presença destes chefes, também neste palco, foi notória e estruturante). Talvez, por isso, poderemos considerar que, em 1974, a Nação estava em crise.

Os relatos que colhemos das experiências vividas pelos participantes nos acontecimentos do Golpe de 16 de Março são a este título bem, eloquentes:

É uma geração iniciada com a guerra (...) A certa altura começo a aperceber-me, como muitos, que cada vez era mais difícil passar a mensagem... era difícil. Via-se isso muito, especialmente, na Escola Prática de Mafra onde só apareciam licenciados com mais cultura. Aqui um pouco menos [Regimento de Infantaria 5]. Tínhamos de responder - é assim porque é assim e acabou. Não sou revolucionário e foi difícil!

Mas as consciências vão sendo despertadas. (...) No meu caso pessoal começo cedo o contacto com os futuros oficiais milicianos. Por exemplo, no meu primeiro pelotão em Mafra é tudo licenciado e todos mais velhos do que eu (1969). Eles não podiam exprimir-se, e não se exprimiam, logicamente. Havia ali diversas ideias, mas de uma forma geral, era tudo contra a guerra colonial. Embora não o expressassem! Achavam que aquilo era um grande sacrifício da sua vida. À medida que os anos passavam o desgaste era grande e começava a ser maior. Estas conversas com oficiais milicianos fazem despertar as consciências dos mais novos. ${ }^{380}$

Os oficiais de carreira, formados para o combate, fiéis a uma disciplina de obediência, alteraram as suas representações. A guerra de contra-subversão foi a doutrina adoptada pelo Estado Novo em 1961. Esta exigia grande número de efectivos e meios. É uma guerra destruidora e agressiva, longa e, por isso, desgastante. Com a sua experiência, mas, sobretudo, com as histórias que ouviram, os oficiais portugueses conheceram o outro lado da guerra. Deste sentimento, surgiram imensas dúvidas, cumplicidades e certe-

\footnotetext{
380 Entrevista com o Coronel Rocha Neves, em Caldas da Rainha, a 11 de Novembro de 2006.
} 
zas determinantes para a vitalidade e firmeza da revolta dos oficiais portugueses.

(...) durante esses 13 anos muita coisa se passou. Nomeadamente muitas idas, afastamentos da família e muita incompreensão sobre as verdadeiras razões da guerra. A guerra, mais não é, do que a continuação da política por meios violentos (...). Assim os militares iam e vinham. Os capitães e sargentos do quadro eram aqueles que mais sofriam com a guerra. Contrariamente à opinião de algumas pessoas que diziam que o capitão ia para a guerra só para enriquecer (...). Preocupava - nos fazer uma comissão de dois anos e depois voltarmos a ir para lá mais dois anos. No ano que passámos cá e perguntávamo-nos se a guerra tem um limite, um princípio, um meio e um fim, e um objectivo.

Qual era o objectivo dessa guerra? Isso era uma dúvida que nós tínhamos. Previa-se ad eternum. (...) A guerra era apenas a imposição de uma vontade política por meios violentos. (...) pressupõe uma subordinação do poder militar ao poder político, mas não subserviência. ${ }^{381}$

As longas noites africanas eram em Angola, onde existiam temperaturas elevadas! Durante o dia era um calor enorme e as pessoas trabalhavam. A partir das 4 ou 5 horas, a meio da tarde, começava a escurecer. Mas as pessoas não se iam deitar e juntavam-se. Ficavam por ali a beber uma cerveja, um gin e conversávamos sobre as nossas família e a evolução política, o que se passava lá fora na Europa. Nós nessa altura não pertencíamos à Europa e estávamos em África. Conversávamos sobre como as outras pessoas resolviam as questões.382

A vida e o ser de todos aqueles que, voluntários ou não, participavam na Guerra Colonial portuguesa mudou. A guerra de contra-subversão protagonizada pelos militares portugueses ganhou um sentido único nas conversas prolongadas longe do conflito, mas dentro dele. As dificuldades

\footnotetext{
${ }^{381}$ Entrevista com o Coronel Gonçalves Novo, em Lisboa, a 8 de Janeiro de 2007.

382 Entrevista com o Coronel Gonçalves Novo, em Lisboa, a 8 de Janeiro de 2007.
} 
sentidas na sociedade portuguesa, o isolamento político português, a opressão política e intelectual imposta pelo Estado Novo foram partilhadas e sentidas nas Companhias. As palavras e os silêncios, as hesitações e as aspirações dos militares constituem o início do processo de decisão, que conduziu à revolução, fortalecendo a sua confiança e ímpeto. ${ }^{383}$

A guerra é como todas as guerras com as suas injustiças, mas criou entre os jovens grandes laços de camaradagem (...) As pessoas estão numa situação de limite, portanto há o sacrifício e o espírito de entre ajuda que leva a que se criem laços para toda a vida. Em termos políticos aquilo que os militares pensavam era que a guerra era feita como todas as guerras, ou a maior parte delas pelo menos para que haja uma solução política final. Foi isso que me levou para a minha quarta comissão. Foi acreditar que o General Spínola apresentava soluções para a guerra (...). A gente sabia que aquilo não levava a nada e o General Spínola tinha uma política de transferência de responsabilidades (...) Era a política de uma Guiné Melhor e a política da Guiné para os Guinéus. ${ }^{384}$

\section{Do 16 de Março ao 25 de Abril}

É pois no quadro desta ambiência mental e de solidariedade grupal que se deve explicar, em boa medida, o trajecto dos militares de Abril. Em se-

\footnotetext{
383 A Publicação do livro Portugal e o Futuro, de António de Spínola, reforçou a convicção daqueles que sentiam de forma gravosa a guerra colonial, na inevitabilidade da solução política para o conflito militar. Esta conclusão emergia das suas vivências. Luís Nuno Rodrigues (na obra Spínola, A Esfera dos Livros, Lisboa, 2010, p. 236-243) carreia vários testemunhos que ilustram este contexto. Vale a pena chamar aqui a atenção para os seguintes registos: a propósito da exoneração dos generais, Ramalho Eanes exalta a personalidade de Spínola, em oposição à daqueles que viviam alienados; Rafael Durão destaca a força das palavras do general, corroborada na sua exemplar experiência de guerra; a "Comissão de Oficiais da Guiné" denuncia o colapso naquele palco de guerra, concomitante ao enfraquecimento da Nação e das suas FA. São também curiosas as palavras de D. António Ribeiro, Azeredo Perdigão, Sá Carneiro, Champalimaud, entre outros. Pressentem que, nas entrelinhas, o general denuncia o princípio do fim da política do Estado Novo.

${ }^{384}$ Entrevista com o Major-General Manuel Monge, em Beja, a 25 de Maio de 2007.
} 
melhante contexto, o Golpe das Caldas acaba por evidenciar, no seio desses grupos, um clima de reforço do comum sentimento de oposição ao Estado Novo, e, sobretudo, por fornecer indicações pragmáticas de manifesta importância estratégica. Estava criado o élan indispensável para a preparação de um golpe militar:

"Para mim as Caldas da Rainha constituíram um momento importante no meio daquele desastre e da prisão dos 200 oficiais, porque deram sinais indesmentíveis e ideias de manobra para o 25 de Abril. Nesta altura pensei: Por causa de uma coluna militar há este dispositivo todo?"385

E se é certo que já na célebre reunião de Cascais a maioria dos oficiais do MOFA presentes concluira que a crise das FA, que sentiam de perto, era apenas um sintoma da profunda crise que bloqueava o país, ali definido como objectivo derrubar o Governo ${ }^{386} \mathrm{e}$, donde, planear um golpe militar e estudar a viabilidade do mesmo, o Coronel Saraiva de Carvalho afirma que "só o 16 de Março é que vai desencadear a resposta premente da acção militar"387.

Não nos deteremos agora sobre a cronologia e cruzamentos interpretativos relativos à factualidade conducente ao 16 de Março, aspectos por nós já tratados em outro trabalho ${ }^{388}$. Interessa-nos, aqui, ficar com a perspectiva dos próprios militares - objecto específico deste artigo - sobre o evento e, genericamente, sobre os rumos e balanços que, na altura, lhes suscitou o episódio das Caldas, até em termos das ilações a tirar para efeitos da sua subsequente movimentação. Neste ponto, os dados disponíveis são os que a seguir se apresentam.

385 Entrevista com o Coronel Saraiva de Carvalho, em Lisboa, a 4 de Julho de 2007.

386 "Saímos da reunião de Cascais convencidos e dispostos a avançar, rápida mas seguramente, para a libertação dos portugueses do jugo fascista - colonialista, a implantação da democracia e a resolução da questão colonial!", Vasco Lourenço, "Ainda o 16 de Março”, Expresso - Revista, 24 de Maio de 1997, p.76.

387 Entrevista com o Coronel Saraiva de Carvalho, em Lisboa, a 4 de Julho de 2007.

388 Joana de Matos Tornada, Nas Vésperas da democracia em Portugal. O Golpe das Calas de 16 de Março de 1974. Coimbra, Almedina, 2009. 
No dia 18 de Março, os Majores Saraiva de Carvalho, Vítor Alves e Melo Antunes encontraram-se para esclarecer o Golpe das Caldas. O Major Melo Antunes mostrou-se preocupado com tal imprudência.

O Major Saraiva de Carvalho, que conheceu de perto as movimentações da noite de 15 de Março e da madrugada seguinte, justificou a precipitação com o espírito da Guiné dos Majores Casanova Ferreira e Manuel Monge. Mas, o Major Melo Antunes afirma que nessa reunião procurou elucidar o Major Saraiva de Carvalho "a perceber o significado político do 16 de Março..."389. Para Melo Antunes não se tratava do espírito da Guiné, mas de uma tentativa de antecipação da linha spinolista "com vista a impor o general Spínola como chefe militar e político do Movimento e impor também, no fim de contas, ao resto das Forças Armadas e ao próprio país uma solução servida de bandeja e que estivesse de acordo com as próprias ideais do general"390. Daí considerar positivo para o Movimento o resultado do Golpe das Caldas ${ }^{391}$.

Vasco Lourenço esclarece que "o 16 de Março, feito no seio do Movimento dos Capitães, é forçado por uma tentativa acelerada do chamado «grupo spinolista” para recuperar o que não tinha conseguido no dia 5 de Março [a defesa da posição de que não era necessário existir um programa político, porque tinham um chefe que indicaria o caminho]"392.

O Major Saraiva de Carvalho replica argumentando que o Golpe das Caldas "fugiu um bocado ao controle da CC do Movimento. O 16 de Março, numa primeira fase, surge no decurso de uma tentativa de evitar a exoneração do Spínola e do Costa Gomes, mas sobretudo do Spínola”393.

Enquanto Vítor Alves, que recusou participar nas movimentações daquela madrugada, considera que "o Otelo estava no Movimento, claro, mas

\footnotetext{
389 Melo Antunes, ob. cit., p.62.

390 Idem, Ibidem, p.61.

391 Idem, Ibidem, p.61.

392 Vasco Lourenço, in Manuel Barão Cunha (coord.), 30 Anos do "25 de Abril-Jornada de Reflexão (Oeiras, 25 de Março de 2004, Casa das Letras/Editorial Notícias, Cruz Quebrada, 2005, p.80.

393 Otelo Saraiva de Carvalho, em entrevista de Ana Sá Lopes e António Melo, art. cit.
} 
também estava com aquele grupinho e sentiu-se obrigado a alinhar com eles"394.

Os testemunhos dos participantes recolhidos referem a utilização do termo "spinolista" como anacrónica. Em Março de 1974, o grupo de oficiais mais próximos do General Spínola, eram aqueles que o próprio nomeou para a Guiné para integrarem o seu projecto "Da Guiné para os Guinéus". Nesta altura, estes militares ${ }^{395}$, que brilharam junto de Spínola, na Guiné, eram olhados com desconfiança pelo Governo ao considerá-los a sua "guarda pretoriana"396. O ministro da Defesa declara que "só depois do 16 de Março, o General Spínola, mais impulsivo, protestou contra a detenção dos oficiais participantes no golpe."397 Mais, no dia 30 de Março, o General Spínola terá tentado visitar os oficiais detidos na Trafaria (embora não tenha obtido autorização do Presidente do Conselho ${ }^{398}$ ).

O General Spínola nunca quis assumir que o Golpe das Caldas seria uma antecipação. Não obstante, sabemos que o General conhecia as movimentações dos oficiais do Movimento. Ouvia-os e, naquela noite procuraram o seu conselho. Também, nessa noite, o General não hesitou em orientar o Major Manuel Monge e o Tenente-Coronel Almeida Bruno. No entanto foi prudente, e afastou-se das movimentações refugiando-se na sua casa de Paredes. Restam ainda algumas dúvidas sobre a capacidade e intencionalidade de Spínola em antecipar-se quer ao MOFA, quer ao General

394 Vítor Alves, em entrevista de Ana Sá Lopes e António Melo, art. cit.

395 Carlos Azeredo recorda que "revoltado com a exoneração de Spínola, enviei ao QG uma declaração em que afirmava que a minha lealdade militar deixava de estar hipotecada aos chefes militares constituídos para continuar ligada aos generais exonerados, pelo que sugeria a minha passagem imediata à reserva. (...) Este meu requerimento de passagem à reserva foi, após o 25 de Abril, encontrado pelo então tenente-coronel João de Almeida Bruno na secretário do ministro do Exército, general Andrade e Silva, com um despacho a determinar que eu fosse presente a uma Junta de Saúde Hospitalar, a fim de passar à reserva por... insanidade mental" (Carlos de Azeredo, Trabalhos e Dias de Um Soldado do Império. Livraria Civilização Editora, Barcelos, 2004, pp. 154-155).

396 O pretorianismo encontra-se na história das revoluções como "um fenómeno político que implica a deposição dos governantes pelos chefes do exército, surge precisamente no período avançado do império romano." (In "Revolução", Dicionário de Política, dir. Norberto Bobbio, Nicola Matteucci e Gianfranco Pasquino, Editora Universidade de Brasília, Brasília, 2ed., 1986, p.1123).

397 J. Silva Cunha, Ainda o "25 de Abril", Centro do Livro Brasileiro, Lisboa, 1984, p.117.

398 Armando Ramos, ob. cit., p.137. 
Costa Gomes, ou seja, no sentido de os afastar do centro de influência política. Apesar de todas estas considerações, o General Spínola colaborou activamente na discussão do programa político do MFA entre 16 de Março e 25 de Abril de 1974.

Poderemos afirmar que o Golpe das Caldas constituiu uma precipitação. Os oficiais reunidos na casa do Major Manuel Monge faziam parte de um grupo de oficiais que, integrados no Movimento, preparavam o plano de derrube do regime. Todavia, avançaram perante a precipitação dos oficiais de Lamego. No dia 19 de Março, estes escreveram uma declaração conjunta sobre os últimos acontecimentos. Nela afirmam que "a crise nacional agudizou-se durante os últimos dias, em virtude de um conjunto de circunstâncias para que os oficiais do CIOE (...) de modo nenhum contribuíram, mas que deles exigiram adequado comportamento"399. Consideram que as suas causas foram o desprestígio das FA e a demissão dos generais desta instituição no dia 14 de Março. Os oficiais do CIOE, "com o objectivo de restaurar a integridade e a independência das Forças Armadas, comunicaram ao Ex.m comandante da unidade a posição que espontânea e unanimemente assumiram” ${ }^{400}$. Junto do comandante, o Coronel José Amílcar Neves, evocaram a sua solidariedade e lealdade com os generais recentemente demitidos e solicitaram a permanência do comandante nas suas funções no comando da unidade. Por fim, os oficiais consideraram que a sua acção não foi precipitada, mas sim fruto de uma "análise serena" e com "o conhecimento possível da situação". Os oficiais do CIOE rejeitaram, a 19 de Março de 1974 , em conjunto, qualquer ligação política ou partidária.

O Golpe das Caldas de 16 de Março de 1974 foi analisado segundo várias perspectivas. Ao reconhece-lo uma simples tentativa falhada, é importante salientar que esta abriu novas oportunidades e que a ligam, indiscutivelmente, ao derrube do regime e à implantação da democracia em Portugal. O Golpe das Caldas teve o seu momento de viragem em casa do

399 "Declaração dos oficiais do CIOE de Lamego", reproduzido na obra de Manuel Bernardo, Marcello e Spínola: a ruptura. As Forças Armadas e a Imprensa na Queda do Estado Novo, 19731974, pp. 200-201. O documento foi assinado por 13 capitães.

400 Idem, Ibidem, p. 200. 
Major Manuel Monge. Poderiam os oficiais presentes pensar que o plano discutido dias antes teria sucesso?

Os Majores Casanova Ferreira e Manuel Monge julgavam que o regime estava frágil e sentiam a premência de uma acção militar (o Major Saraiva de Carvalho consideraria estes pensamentos provocados pelo espírito da Guiné, aludindo à recente chegada destes oficiais daquele território, bem como à sua longa e desgastante experiência de guerra). Além disso, o Major Manuel Monge defendia que uma companhia poderia abanar o regime de forma a derrubálo. Nesta noite, os oficiais reunidos receberam o telefonema de Lamego que precipitou certamente a sua acção. Com uma coluna a caminho de Lisboa, era necessário organizar e coordenar as forças do Movimento. Os Majores Casanova Ferreira e Manuel Monge presenciaram o entusiasmo dos oficiais de várias unidades do país, no dia 12, quando decidiram colaborar num golpe militar, embora, no dia 13 de Março, tivessem suspendido o plano. As unidades recuaram, justificando-se com a ausência da ordem do General Spínola e uma estratégia inesperada. Aliás, os Pára-quedistas afirmaram que já tinham uma ordem de operações. Contudo, o Major Manuel Monge considerava que estes não apoiariam qualquer acção militar do Movimento, ao considerar que, dificilmente, tomariam uma posição contra o seu comandante).

De toda esta complexidade e ambiguidade, tinha profundo conhecimento o Major Saraiva de Carvalho. Este oficial compreendeu que o Golpe das Caldas foi um dos "acontecimentos que tornam possível uma Revolução ao pôr a nu a inabilidade da elite em manter o monopólio da força" ${ }^{401}$, ou seja, um "acelerador". Se por um lado a cisão no seio da instituição militar (pilar fundamental do Estado Novo, particularmente num cenário de guerra disperso e longo) se concretizou, definitivamente, com a demissão dos generais Costa Gomes e Spínola, por outro lado só os acontecimentos das Caldas afectaram a disciplina, a organização, a lealdade das FA e de outras instituições da segurança interna do país. A rápida desagregação do pilar fundamental do regime, abriu caminho à democracia portuguesa.

401 C. Johnson Revoludies, Stanford, 1964, citado por Gianfranco Pasquino, "Revolução”, Dicionário de Política, dir. Norberto Bobbio, Nicola Matteucci e Gianfranco Pasquino, Editora Universidade de Brasília, Brasília, 2ed., 1986, p.1126. 
O Golpe das Caldas de 16 de Março de 1974 projectou o MOFA no futuro. Aniceto Afonso esclarece que "exerceu também sobre o Movimento uma pressão definitiva, no sentido da irreversibilidade de um desenlace violento; lançou um novo alerta para o exterior, avisando que a situação interna portuguesa se aproximava de uma clarificação, fatalmente conflituosa" ${ }^{402}$. Ideia que melhor se compreende quando recuperamos o essencial sobre a preparação do Golpe de Abril.

Otelo Saraiva de Carvalho afirma, na sua obra Alvorada em Abril, que existia a preocupação das movimentações de 16 de Março revelarem à DGS a organização e finalidade do Movimento. Para ele os objectivos do Movimento estavam em perigo devido à pressão que a polícia política poderia exercer. Esta preocupação era partilhada pelo Major Vítor Alves, embora se manifestasse um pouco mais optimista ${ }^{403}$, mas especialmente pelo Major Melo Antunes. Todavia, este oficial tinha a missão de elaborar um programa político do Movimento "que extraísse o que de mais válido existia no Manifesto aprovado por maioria no plenário do dia 5 e que se adiantasse em mais pormenor e substância" ${ }^{404}$.

Tornava-se fundamental aproveitar o entusiasmo suscitado pelo Golpe das Caldas para motivar os militares "para uma coisa a sério". Otelo Saraiva de Carvalho confessa que "grande parte do meu optimismo e confiança assentavam naquilo que, tão peremptoriamente, Avelar de Sousa nos garantira quanto à possibilidade de intervenção dos pára-quedistas, na reunião de 13 de Março no Dafundo" ${ }^{405}$.

No dia 24 de Março de 1974 realizou-se uma reunião de oficiais do MOFA (em Oeiras, na casa do Capitão Candeias Valente). Estiveram presentes 21 elementos que exigiam explicações sobre a tentativa do RI5. Choveram críticas, mas o Major Saraiva de Carvalho apresentou a sua proposta - "era preciso enveredar definitivamente pela solução militar, ou seja, estudar a

402 Aniceto Afonso, "O Movimento dos Capitães", in História de Portugal (dir. João Medina), vol. XIV, Clube Internacional do Livro, Amadora, s/d, p.21.

403 Otelo Saraiva de Carvalho, Alvorada em Abril.Ulmeiro, Lisboa, $3^{\text {a }}$ ed. s/d., p.296.

404 Idem, Ibidem, p.295. O Major Melo Antunes entregou o documento, no dia 22 de Março, antes da sua transferência para os Açores.

405 Idem, Ibidem, p. 296. 
situação e articular forças. Era necessário fazer uma ordem de operações" 406 -, esclarecendo que estava preocupado com os oficiais presos, que por certo seriam pressionados a revelar a identidade dos elementos do Movimento, bem como da sua organização.

O Major Saraiva de Carvalho sugeriu que esta fosse a última reunião do Movimento ao pretender iludir o Governo. Por outro lado, observavam que a DGS se preocupava, sobretudo, com as mobilizações em redor do $1 .^{\circ}$ de Maio. Lisboa estava cheia de grafites alusivas ao Dia do Trabalhador, o que tornava fácil aos militares dissimular as suas movimentações. Extinguiram as comunicações entre unidades e elementos de ligação, enquanto o Major Saraiva de Carvalho absorveu a organização do Golpe.

No dia 16 de Março, as tropas mobilizadas não tinham plano de ligações e desconheciam as forças inimigas que iriam enfrentar. O Major Saraiva de Carvalho identificou na Rotunda da Encarnação as unidades militares melhor preparadas para defesa do regime (LP, as forças do RC7, a GNR, a PSP e a DGS). Quando assumiu a responsabilidade de elaborar um plano operacional, começou por recolher informações.

O Major Saraiva de Carvalho tinha um primo ${ }^{407}$, o Major Velasco, destacado no Quartel-General da GNR no Largo do Carmo. Junto deste reuniu informações sobre a GNR (dados sobre armamento, equipamento, pessoal, rondas, os pontos importantes que aquela instituição militar fiscalizava), pois era uma forma inimiga ${ }^{408}$. Como o major estava no Comando-Geral e

406 Entrevista com o Coronel Saraiva de Carvalho, em Lisboa, a 4 de Julho de 2007.

407 O Major Saraiva de Carvalho não falava com o primo há muito tempo, e na lista telefónica encontrou o seu contacto. Telefonou-lhe para a casa e disse-lhe que gostava de lhe dar um abraço, pois há muito tempo que não se viam. Quando se encontraram (na casa de uma avó do Major Saraiva de Carvalho e tia do Major) o Major Velasco perguntou-lhe por que razão se tinha lembrado dele. O Major Saraiva de Carvalho respondeu: "Ó, pá, vou fazer um golpe de Estado e preciso da tua ajuda" (segundo o relato do Coronel Saraiva de Carvalho, em entrevista, em Lisboa, a 4 de Julho de 2007).

408 "Nessa primeira conversa sobressaiu o interesse de Otelo em conhecer as frequências da rede de transmissões da Brigada de Trânsito (BT), a preocupação que tinha por saber se a GNR tinha requisitado ao depósito de Material de Guerra espingardas automáticas "G3" e sobretudo a curiosidade que manifestou ao tomar conhecimento nesses dia de que a GNR se encontrava em fase adiantada de recepção de viaturas blindadas Shorland. Ainda nesse conversa [o Major de Inf. Fernando Velasco] pediu a Otelo a discrição na sua participação e ainda para não ser informado do dia em que se iria desencadear a acção." (in Major de Inf. a Reinaldo Andrade, "A Revolução de Abril 
era adjunto das operações, tinha acesso a estas informações. O seu primo ainda perguntou se era a sério, mas, dias depois, entregou ao Major Saraiva de Carvalho tudo o que precisava ${ }^{409}$. Também contactou um oficial que estava no Estado-maior do Exército (a quem pediu informações sobre a LP e DGS), bem como o Major Sanches Osório que estava colocado na $4^{\mathrm{a}}$ Repartição Logística do Exército.

Antes do 25 de Abril, com a ordem de operações já elaborada, o Major Saraiva de Carvalho conversou com os majores Hugo dos Santos e Vítor Alves. O primeiro considerava que se devia concentrar todas as forças do Movimento numa grande área e exigir a queda do Governo. O Major Saraiva de Carvalho discordava, porque considerava que numa acção militar o factor fundamental é a surpresa. Entendia que se concentrassem as forças num único espaço, "dariam a possibilidade ao inimigo (o Governo) de mobilizar todos os meios ao seu alcance, que cercariam o local e isolariam as forças do Movimento incapazes de reagir (cortavam a água, o gás, o telefone, os abastecimentos e a luz). Além disso, com o Pacto Ibérico em vigor a Força Aérea dos dois países poderia assaltar a força do Movimento. Era uma situação impossível porque o Governo poderia demorar muito tempo a reagir.” ${ }^{10}$ Para o Major Saraiva de Carvalho a acção só triunfaria se fosse rápida e ofensiva, atingindo objectivos essenciais e impedindo a hierarquia de dar ordens. O Major Vítor Alves afirmou que concordava com Hugo dos Santos, mas confiava no Major Saraiva de Carvalho que confirmava que a sua ordem de operações era exequível e tinha grandes probabilidades de sucesso. Para o Major Saraiva de Carvalho só havia uma solução: "ganhar

de 74 e o Papel da Guarda I" Pela Lei e Pela Grei. Revista da Guarda Nacional Republicana, Ano XVII, n. ${ }^{\circ}$ 65, Janeiro - Março 2005, Lisboa, p.37).

409 No artigo do Major de Inf. ${ }^{a}$ Reinaldo Andrade é relatado que "cerca de uma semana depois do 16 de Março, Otelo Saraiva de Carvalho encontra-se com o seu primo, Major de Inf. ${ }^{a}$ Fernando Hugo Bélico de Velasco" (Idem, Ibidem, p.37). "Efectivamente as Unidades da Guarda, que tinham intervido, activamente, no 16 de Março, foram as que actuaram, agora passivamente, no 25 de Abril." (Idem, Ibidem, p.38.). Pouco antes do 25 de Abril foram contactados pelo Movimento o comandante do Batalhão n. ${ }^{\circ}$, o comandante do Batalhão n. ${ }^{\circ}$ 2. O Major Hugo dos Santos contactou pessoalmente o comandante do Batalhão n. 5 e outros comandos da GNR foram, também, abordados.

410 Coronel Saraiva de Carvalho, em entrevista, em Lisboa, a 4 de Julho de 2007. 
em menos de 24 horas; não podíamos permitir que ocorresse uma guerra nas ruas." ${ }^{411}$

De outro modo, o Golpe das Caldas evidenciou a estratégia que o Major Saraiva de Carvalho depois delineou para o Golpe Militar de 25 de Abril de 1974. Ao utilizar as três principais vias de acesso a Lisboa e uma unidade como isco para as forças governamentais, possibilitava a tomada de importantes alvos por outras unidades. "Os objectivos principais eram o quartel-general, a rádio e a televisão, que seriam tomados enquanto estava toda a gente entretida com a coluna da EPC - esta ideia resultou exactamente do aparato governamental que vi no 16 de Março.” ${ }^{\prime 2}$

Pouco antes do 25 de Abril, na casa do Major Saraiva de Carvalho, em Oeiras, o Capitão Salgueiro Maia recebeu com espanto a sua missão.

Otelo - Tu tens de sair com uma coluna mais forte!

Salgueiro Maia - Mas só tenho uma companhia de instrução que não sabe disparar!

Otelo - Não interessa, porque sais com os blindados, os militares equipados com armas e capacetes. O que importa é o aparato e que vás pelos itinerários principais da cidade! Entras pela Segunda Circular, segues pelo Campo Grande, Entrecampos, Avenida da República, Saldanha, Marquês, Avenida da Liberdade, Restauradores, Rossio, Rua do Ouro e ocupas o Terreiro do Paço. És o chamariz e fazes o maior alarido que puderes. Percorres Lisboa com blindados às 3 ou 4 da manhã. A malta é alertada e vai ter contigo. Entretanto ocupamos outros pontos estratégicos.

Salgueiro Maia - E se aparecer uma força do regime?

Otelo - Ó pá, aí é tramado. Quem souber disparar, dispara, mas não acredito que haja alguém que confronte uma coluna de blindados com pequenas armas ${ }^{413}$.

411 Coronel Saraiva de Carvalho, em entrevista, em Lisboa, a 4 de Julho de 2007.

412 Entrevista com o Coronel Saraiva de Carvalho, em Lisboa, a 4 de Julho de 2007.

413 Segundo o relato do Coronel Saraiva de Carvalho em entrevista, em Lisboa, a 4 de Julho de 2007. 
O Capitão Salgueiro Maia, no final da exposição, colocou duas questões: "Há programa político para sustentar a acção militar? Os generais comandam a operação?” Para o Major Saraiva de Carvalho esta questão era desagradável, logo se lembrando do Capitão Morgado da EPC no dia 13 de Março. Otelo Saraiva de Carvalho sabia que existia a possibilidade do Capitão Salgueiro Maia recuar, o que impedia qualquer acção (tal como aconteceu no 16 de Março); logo, respondeu afirmativamente ${ }^{414}$. Para Otelo Saraiva de Carvalho a grande dúvida era a população, mas havia a grande esperança da sua adesão em massa. "A pouco e pouco, tudo se conjugava para que o golpe militar se tornasse viável, aos oficiais empenhados não restassem objecções e antes se verificassem um conjunto de condições propícias ao seu êxito. A disponibilidade de Costa Gomes e Spínola, a extensão do empenhamento militar a todas as unidades mobilizáveis, os compromissos da Armada e da Força Aérea em não permitirem que o Movimento fosse hostilizado após o desencadeamento da acção, tudo transmitia uma ideia de solidez que à acção do 16 de Março decididamente faltara" 415 .

No final deste trajecto cujos contornos procurámos esboçar, fique uma palavra para o muito que, a este nível, a investigação tem ainda para fazer. No nosso caso, depois de estudar os passos incertos do Golpe das Caldas persiste por analisar com maior profundidade o sentido do olhar do próprio Estado Novo sobre essa particular conjuntura. Um dos espólios que importa ser tratado pelos historiadores é o dos inquéritos de investigação aos militares presos. Esta documentação poderá evidenciar o grau de conhecimento ou desconhecimento das autoridades militares, bem como esclarecer as ligações ou movimentações ocorridas, noutras unidades militares, naquela madrugada e, mais amplamente, em todo aquele âmbito. Outro dos caminhos que falta percorrer, imprescindível para o entendimento do fim do regime, mas, sobretudo, dos homens que viabilizaram a democracia portuguesa, é definir os vários contextos e acontecimentos que

$414 \mathrm{Na}$ verdade, mais tarde, no Quartel do Carmo o Capitão Salgueiro Maia comunicou ao Presidente do Conselho que obedecia ao comando do General Spínola e Costa Gomes, embora conhecesse a existência dos oito generais contactados (in Fernando Salgueiro Maia, entrevistado por Adelino Gomes, art. cit., p.14.

415 Aniceto Afonso, "O Movimento dos Capitães", p.22. 
Portugal 1974 • Transição Política em Perspectiva Histórica

determinaram que a leitura histórica do Golpe das Caldas ficasse refém das dinâmicas conflituantes geradas entre o MFA e o general Spínola. 